Journal of Computer Science 8 (1): 41-47, 2012

ISSN 1549-3636

(C) 2012 Science Publications

\title{
Linear Protection Schemes Analysis in Scattered Placement Fiber-To-The Home-Passive Optical Network Using Customer Access Protection Unit Solution
}

\author{
${ }^{1,2}$ Mohammad Syuhaimi Ab-Rahman, \\ ${ }^{1}$ Siti Asma Che Aziz and ${ }^{1,2}$ Kasmiran Jumari \\ ${ }^{1}$ Department of Electrical Electronics and Systems Engineering, \\ Faculty of Engineering and Built Environment \\ ${ }^{2}$ Institute of Space Science (ANGKASA), \\ University Kebangsaan Malaysia, \\ 43600 UKM Bangi, Selangor, Malaysia
}

\begin{abstract}
Problem statement: This study highlights on restoration scheme proposed against failure in working line at the drop region for Fiber-To-The Home (FTTH) with a Passive Optical Network (PON). Whereas PON is a system that brings optical fiber cable and signals all or most of the way to the end user. Approach: Survivability scheme against failure is focused on scattered residence architectures and it is applied in the ring and tree topology respectively by means of Customer Access Protection Unit (CAPU). CAPU will be installed before the ONU and ensure the signal will find the alternative path when failure occurs at the specific line. Our proposal scheme is low cost and applicable to any residence architecture. The advantage of this scheme is the failure at fiber line can be recovered until three levels to make sure the optic signal flow continuously to avoid any application disturbance. Two type of restoration scheme is proposed by means of linear protection (tree) and migrated protection (ring). FTTH based network design is simulated by using Opti System 7.0 in order to investigate the power output and BER performance at each node in the tree and ring protection scheme in scattered placement. This study we perform an analysis on linear protection scheme that consisting of two model a) Line to Line (L2L) protection and CAPU to CAPU (C2C) or Shared protection. However the migration of tree to ring topology to enable the signal flow continuously in the case of failure occurs specifically in random or scattered placement topology has been highlighted in our previous publication. Results: The signal will be divided into section; drop and pass through and the ratio is significant to determine the number of user allowed and achievable distance. Output power for optical nodes could be slightly improved by varying the pass through and drop signal ratio. Conclusion: Our proposal is the first reported up to this time in which the upstream signal flows in anticlockwise in ring topology when the restoration scheme activated.
\end{abstract}

Key words: Customer Access Protection Unit (CAPU), Fiber-To-The Home (FTTH), Optical Network Unit (ONU), Optical Line Terminal (OLT), Remote Node (RN)

\section{INTRODUCTION}

Survivability in FTTH network is an important issue. It has been discussed in optical network by earlier studies. When a network transfers more data, the total interruptions due to network failure or attack become important issue for consideration (Rejeb et al., 2010) (Ab-Rahman et al., 2011a). Therefore, many authors have come out with innovative design of new techniques and methods to increase the survivability in the distribution area especially scattered placement to ensure the traffic can be sent continuously in the case of failures occurs. The signal can choose one line to go through the Optical Network Unit (ONU) when the failure is occur in the other line (Han et al., 2007).

Two major fibers placed on two lines which are located in the tree and ring network. Every linear path (tree lines), aing lines would be duplicated with the protection line. Protection line will be used in the event of any failure at the working line. Ring line is also

Corresponding Author: Mohammad Syuhaimi Ab-Rahman, Department of Electrical Electronics and Systems Engineering, Faculty of Engineering and Built Environment, University Kebangsaan Malaysia, 43600 UKM Bangi, Selangor, Malaysia 
equipped with two lines for each optical node that is working line and protection line. Protection line is used when there is any failure on the working line. Then, the optical signal will have four alternative routes that have been chosen to carry out the optical signals to transfer to each receiver. The downstream signal will go through the main fiber in a linear path (tree line) and the signal goes through an optical splitter, to distribute power into multiple recipients. Hence, under normal conditions without failure, the optical signal flows through the working line, but if failure occurs in working line, protection line will be activated. Subsequently, the signal enters the optical coupler and a signal in here will be divided according to the percentage of $1-n \%$ for the pass signal component; $n \%$ is the portion of drop signal component. The drop signal will be dropped directly to the recipient. Thus, the ratio of signal power that is already small and enough to be accepted by receiver.

Elliot wave explained about zigzag theory that being used for mechanism protection with various fallouts (multi drop) by connecting every working and protection line in CAPU (Customer Access Protection Unit) the authors group designed. According to Aziz et al. (2009), CAPU is a protection against fiber fault in fiber line that will also being placed in customer enduser in order to perform as the smart restoration if there is uncertainty of fiber cut occurring in distribution region. Figure 1 shows two restoration scheme proposed to cater the breakdown problem occurs in the FTTH-PON. In tree topology, each line connected to ONU is installed with pair fiber. If the working line fails, the traffic will be switched to the protection (stand by) fiber (Fig. 1a). But if the failure is slightly critical, the traffic will be sent through the neighbor's line by utilizing CAPU. The segmentation is activated and the rest and unaffected ONUs receive the signal directly from the optical splitter. If the major problem happens in the network such as cable cut, device dysfunction and others, the only way is to migrate the topology from tree to ring by means of migrated protection as shown in Fig. $1 b$. However the detail discussion on ring restoration properties was already highlighted in our previous article.

Previous research: For comparison, there are two options proposed in the study of Langer et al. (2004). First, by doubling the transceiver and installing new fiber to create a separate password associated with the user. Second, by increasing the overall network access if customers demanded higher. However, by doubling the transceiver at both ends and has two separate fiber routes the center will provide a less economical for the network. So, for this research, simulation analysis for the linear protection path that authors design produce output power almost the same for all optical node, regardless the position of the node. The linear protection signal is separate by splitter and the power dropped it not occur at each optical node. Signal for ring path become optimum with adjusting drop signal (n \%) and pass signal (1-n \%) at optical coupler. From the observation, the average output power is $-23 \mathrm{dBm}$.

In a ring network topology, the protection scheme from Zhao (2005) has a large conventional ring and backup transceiver, used to protect the damage at one point. Among the disadvantages in a ring topology is use a lot of fiber, attenuation of the signal is high and several other long-term problems. To solve this problem, authors used the feeder fiber coupling with a small ring hybrid which was introduced in the study (Hossain et al. 2005). This scheme minimizes the use of fiber and ensures that no data packets are lost with the components ready to standby. However, the ONU is more complex in this scheme and $1+1$ protection scheme has a low market performance due to high costs. In addition, the study Hwang et al. (2009) proposed protection scheme through a close partnership with the PON-ONU to avoid over bridge device in the EPON network. In addition, the proposed network coverage provides network access to large-sized mesh and access networks capable of high accessibility and a fast recovery (Langer et al., 2004). At present, the scheme of protection for future generations also aims to implement protection mechanisms 1: $\mathrm{N}$ because is more efficient that require the use of optical switches $1 \mathrm{xN}$ (Appelman and Zalevsky, 2004). The basic concept of switching is often used for opto-mechanical technology. The study of Han et al. (2007) also propose a hybrid architecture to protect the failure protection in WDMPON multipoint and network design is by a full duplex configuration. In which all areas, including fiber module is equipped with redundant (duplicate full) and two working fibers and protection fibers are used during normal conditions. However, protection scheme of Chan et al., (2003) proposed a network architecture based on WDM protection that will provide protection against damage to the fiber bidirectional 1:1 between the remote node (RN) and the ONU. If damage occurs online, which carry data signals are transferred via the adjacent ONU protection under the proposed scheme. Ab-Rahman et al. (2011b and 2011c) has proposed the survivability scheme based on the Optical Cross add and Drop Multiplexer (OXADM) to cover the protection in drop/distribution area. Two restoration schemes are introduced to cater the problem of breakdown and will be activated according to the types of failures by means of linear protection and shared protection. 


\section{MATERIALS AND METHODS}

Art of design: The designed network protection scheme is a combination of the linear and ring protection. Then the simulation analysis is conducted from node to node and is divided into two main parts, namely linear and ring protection schemes. Each part of the protection scheme has been reviewed. The output power for each node has obtained in the normal state (without failure). The maximum distance that can be achieved with the sensitivity of every different protection schemes and also the maximum number of nodes is depending on the different of sensitivity. Sensitivity values are used for the node to node analysis which starts at $-25,-30,-32$ and $-35 \mathrm{dBm}$.

Figure 1 (a) shows design of the linear feeder route for tree topology or linear network. The wavelength 1550 and $1490 \mathrm{~nm}$ will be multiplexed to get through network protection. CAPU was designed with four alternative routes protection to transfer optical signal if line is breakdown. Two major lines are proposed in this network architecture for tree and ring topology. Both major lines are combined in this CAPU (Ab-Rahman et al., 2009). Two major fiber was placed on two lines; tree and ring line. Each linear path (tree line), working line will be duplicated with protection line. Protection line will be used in the event of any failure to the working line. Ring line is also equipped with two lines for each optical node which are protection and working line. Then the optical signal will have four alternative routes that will be selected to carry the optical signals to each receiver. Figure 1 (b) is a design of dropped region for linear protection scheme when signal from feeder will be separate to five receivers and after that flows through optical nodes. The optical signal from feeder region will be split by $1 \times 5$ optical splitter to reach to the five number ONU. Before reaching to the ONU, optical signal must passing and will be divided according to percentage in every node optic. Optical node consist of optical switch, optical coupler, optical circulator and de-multiplexer. Figure 1c indicates optical node components which bring signal for linear path. If both of working and protection line are failure, ring line will be activated. Signal from ring line will flow through major fiber and optical coupler. Here, signal will be divided into $2 \%$ of power; $1-\mathrm{n} \%$ pass signal and $\mathrm{n} \%$ drop signal. Drop signal enter to optical switch $2 \times 1$ and optical circulator. Drop signal will be dropped directly to the recipient. Thus, the ratio of signal power already small enough to be accepted on a receiver. The pass signal will transfer to the optical node (signal out). Optical signals out from the previous node will be the input signal to the optical node and the next optical node.

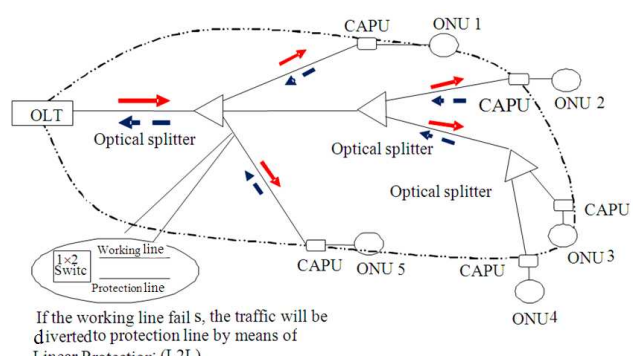

(a)

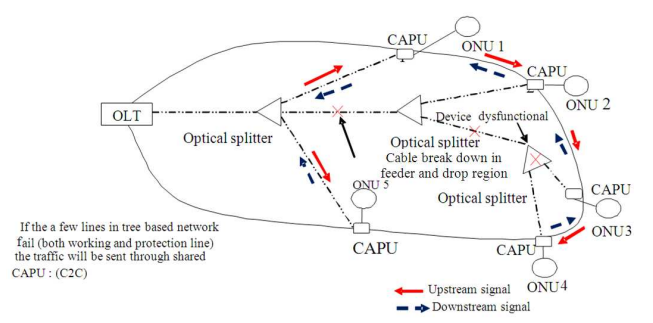

(b)

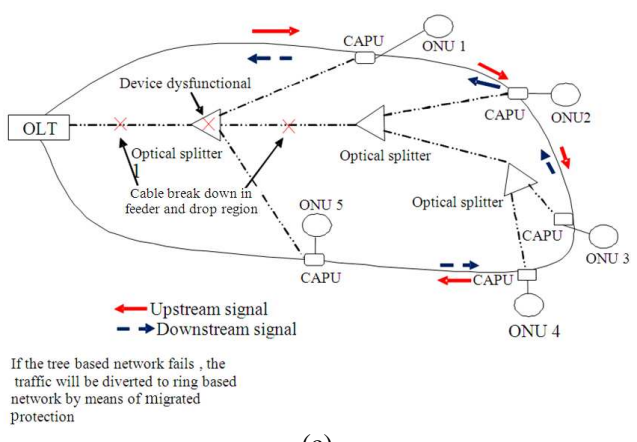

(c)

Fig. 1: Two restoration schemes are proposed and be activated according to PON (a) Zero Fault Condition (b) Linear Protection (c) Migrated Protection

Figure 1c shown for ring network simulation stage, point a signal path for whole ring network which have 5 optical nodes connected to each other. Drop signal from optical coupler with ratio $\mathrm{n} \%$ will transfer through optical switch $2 \times 1$ and receiver using optical circulator. Pass signal flow into optical switch $2 \times 2$, where the optical switch control with ACS to choose which line will be activated. Signal flows from node to node (ring line) also have 2 line fibers. ACS controlled all the optical switch function to change path. Figure 5 shows component where optical signal pass in ring network. From the network architecture security authors designed, linear and ring line terminal are used in Optical Line Terminal for downstream signal. In normal condition, linear line terminal would transfer downstream signal into linear line. Thus, ring line 
terminal is static and not activated if failure is not occur on both of linear line.

Simulation of distance accessibility in this research, authors has determined the increase, at the same time when sensitivity at linear and ring path increased. The increase of user optical nodes would be analyzed by simulation. For sensitivity of $-35 \mathrm{dBm}$, the number of optical nodes could be added to the 10 nodes by adjusting the percentage ratio of the optical coupler. Generally for EPON FTTH network, it's involving relatively high data rates of $1.25 \mathrm{Gbps}$ to obtain the minimum bit error rate of 10-09. So, according to standard IEEE 802.3ah EPON protocol budget authority, this architecture design of protection and restoration FTTH-PON is at $26 \mathrm{~dB}$ by PX-20D for the fiber length of $20 \mathrm{~km}$.

\section{RESULTS AND DISCUSSION}

Output power for each node of linear protection scheme: Signal flows through linear protection and then joins into optical coupler. After that, it will be divided into two signals; one pass signal and the other drop signal. For the analysis of this case study, the first optical coupler is adjusted to a ratio of $50: 50 \%$ which is $50 \%$ for drop signal and $50 \%$ for pass signal. The $50 \%$ pass signal will be combined with a new signal from the next optical node. Then, after observing the performance each optical node in term of output power, the ratio of the optical coupler is adjusted to obtain optimum output power for each receiver at the optical node. The pass signal (1-n) \% drop signal of $n \%$ is adjusted. In the design of linear protection, signals through linear protection line would not have power dropped when they flow from optical node to other optical nodes until the last node. This is because the power of optical signal will be split to each node. It will be in effect when transmitted input power to the Optical Line Terminal (OLT) separate by optical splitter upon entering each optical node. In contrast to the ring network, the power output by each node is expected to shrink by follow the position of the optical node.

Figure 2 shows the output power of two wavelengths (1550 and $1490 \mathrm{~nm}$ ) respectively at a signal pass and loss when the coupling ratio was adjusted to 50:50\%. Lower output power of drop signal is observed at the first node, -31.228 (1550) and $31.978(1490 \mathrm{~nm})$. This may be due on the first node that does not have the power combination of the optical coupler on the previous node and make it the lowest power than the other optical nodes. The lower pass signal occur at second node is -29 593 (1550) and -30 $343(1490 \mathrm{~nm})$. From the present output power, the receiver sensitivity of $-32 \mathrm{dBm}$ can be applied for linear protection scheme when the optical coupler is adjusted to $50: 50 \%$ for the signal pass and drop. Subsequently, the percentage ratio of coupler is adjusted randomly to obtain the lowest output power and it is same for each optical node. Thus, the adjusted ratio percentage is shown in Fig. 3 (inside) whereas the ratio for 5 optical nodes is individually adjustable. Figure 3 shows the output power results when the coupler ratio is adjusted as shown in inside box. The highest output power obtained at the fifth node where the value is $26.568 \mathrm{dBm}$ (drop signal of $1490 \mathrm{~nm}$ ) and lowest power at second node is $-30.847 \mathrm{dBm}$ (drop signal $1490 \mathrm{~nm}$ ). When the pass signal goes high at the second optical node (pass signal $1490 \mathrm{~nm}$ ) then, at the same time, signal goes high at the first optical node $-34.656 \mathrm{dBm}$ (1490 nm signal to go). From the drop signal output power, the sensitivity would be reduced to $-31 \mathrm{dBm}$. Therefore, by adjusting the ratio of the coupling, $1 \mathrm{dBm}$ sensitivity could be reduced.

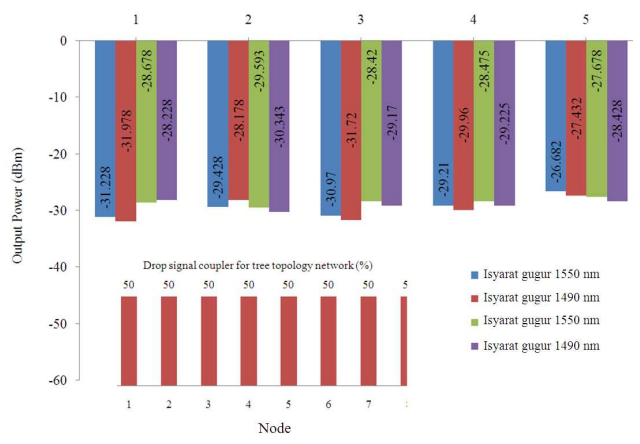

Fig. 2: Output power for the 5 nodes; drop signal and pass signal (1550 and $1490 \mathrm{~nm}$ ) when the oupler is adjusted ratio 50: 50\%. Inside: Percentage of optical coupler ratio adjust for linear path protection scheme

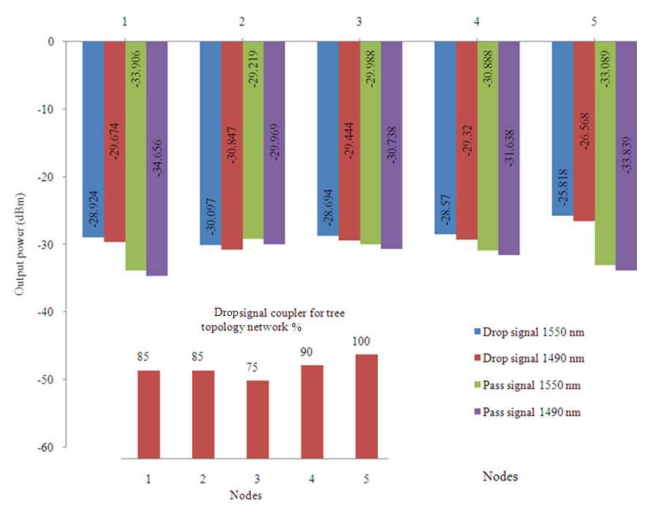

Fig. 3: Power output for the 5 nodes; pass and drop signal (1550 and $1490 \mathrm{~nm}$ ) when the ratio of the coupler iIs adjusted at randomly. Inside: Percentage of optical coupler ratio adjust for linear path protection scheme 
Achievable distance: The Simulations were conducted to study the maximum distance that can be achieved for a linear path protection according to the ratio of pass and drop signal. This analysis starts with evaluation of output power of the distance $(\mathrm{km})$ that can be achieved in each of the optical path and thus, the sensitivity can be determined afterwards by the output power obtained. The maximum distance that can be achieved has been measured when the receiver sensitivity is set at $-25,-30$, 32 and $-35 \mathrm{dBm}$. The cut off distance is defined by maximum $Q$ factor parameter which is 6 acceptable values through BER analyzer on Opt system software. The specifications used to run the simulation were as follows:

\section{Network specification:}

\begin{tabular}{|c|c|c|}
\hline \multirow{3}{*}{$\begin{array}{l}\text { Launched signal power } \\
\text { Data transmission rate }\end{array}$} & $=$ & $0 \mathrm{dBm}$ \\
\hline & $=$ & 1.25 Gps for \\
\hline & & $\begin{array}{l}\text { downstream (EPON } \\
\text { standard) }\end{array}$ \\
\hline Sensitivity of photodetector & $=$ & $\begin{array}{l}-25,-30,-32 \text { and }- \\
35 \mathrm{dBm}\end{array}$ \\
\hline Thermal noise & $=$ & $\begin{array}{l}0.1152572631 \mathrm{e}-021 \\
\mathrm{~W} / \mathrm{Hz}, \\
11.817578125\end{array}$ \\
\hline & & $024 \quad \mathrm{~W} / \mathrm{Hz}$ \\
\hline & & 4.005859375 e-024 \\
\hline & & $\mathrm{W} / \mathrm{Hz}$ \\
\hline & & 1.0764648375 \\
\hline & & $024 \mathrm{~W} / \mathrm{Hz}$ \\
\hline
\end{tabular}

Maximum range of advanced analysis to study the linear distance of the route. This linear route will be divided into two main parts, namely the adjustment of the coupling ratio is set at 50\%: $50 \%$ and the ratio of the coupler is changing. Performance in these two conditions will be compared by the maximum distance that can be achieved.

Ratio of drop and pass through signal-50:50\%: Adjusted distance varies from 10-120 km. Figure 4 (a) shows the output power when the fiber length at a distance to signal loss. Power output decreased linearly with increase in fiber length $(\mathrm{km})$. Achieved the highest output power available at the optical node 5 and the lowest output in the first optical node. There is a difference of $5.2324 \mathrm{dBm}$ between the first optical nodes and optical nodes to 5 .

Consider the optical node to 5 , the output power of $-25,-30,-32$ and $-35 \mathrm{dBm}$ respectively the fiber length at a distance of $11,35,46$ and $61 \mathrm{~km}$. Considering the first optical node, the power output at $-30,-32$ and -35 $\mathrm{dBm}$ find their fiber length at a distance of $9,18.6$ and $33.6 \mathrm{~km}$. So to achieve a high range on the network, a wide dynamic range at the receiver is required. Figure $4 \mathrm{~b}$ shows the value of maximum $\mathrm{Q}$ factor which is achieved for each node as the 50:50\% ratios at sensitivity of $-25 \mathrm{dBm}$. As we can see, optical node 5 have accessed to the highest distance at 12 and $4.4 \mathrm{~km}$ for the optical node 2 while the other nodes have severed with Q factor reduction due to insufficient sensitivity of the receiver when the power loss occurred at the nodes are very high. We found the $\mathrm{Q}$ factor decreases exponentially with increasing of fiber distance.

Ratio of drop and pass through signal-n: (1-n)\%: This time on the coupling ratio is adjusted to a certain ratio so that the loss can be reduced to each optical node. Figure 5a shows the output power versus distance is obtained when the coupling ratio of the linear path varied randomly (see the box inside). As we can see, optical node 5 has obtained the highest output power as compare to other optical nodes and optical nodes 4 has obtained the lowest output power. In this case, 4.2925 $\mathrm{dBm}$ difference between optical nodes to 5 and node 4 . The measured output power at node 5 is at sensitivity of $-25,-30,-32$ and $-35 \mathrm{dBm}$ has achieved different distance of 12, 36, 47 and $62 \mathrm{~km}$. By considering the optical node 4 (the lowest output power) output power at $-30,-32$ and $-35 \mathrm{dBm}$ we find their length of fiber at a distance of 13.06, 23.75 and $39.1 \mathrm{~km}$. As obtained from the results, only $1 \mathrm{~km}$ can be increased from the adjustment of the ratio of the optical coupler. Hence, output power for optical nodes could be improved slightly by varying the pass through and drop signal ratio.

Figure $5 \mathrm{~b}$ shows the maximum value of the $\mathrm{Q}$ factor is achieved for each node at the different percent ratio of drop signal and $\mathrm{Q}$ factors were obtained at -25 $\mathrm{dBm}$ sensitivity. Optical nodes 5 have access to the highest distance from other nodes which is $12 \mathrm{~km}$ and the other nodes has weakened with severe $\mathrm{Q}$ factors and cannot achieve the $\mathrm{Q}$ factor of $\sim 6$.

Simulation continues to increase the sensitivity of $30 \mathrm{dBm}$ for the receiver to see the maximum distance that can be achieved for each optical node. This is important to predict the distance that can be achieved in different sensitivity on the linear network. Figure 5c shows the distance that can be achieved at $-30 \mathrm{dBm}$ sensitivity. As expected the maximum distance can be increased for each recipient. Based on the minimum line Q factor for each optical node, the distance is found to be $17.62,24,375,25.5,26,411$ and $40.35 \mathrm{~km}$ respectively for the optical node 2 , optical nodes 3 , optical node 4 , optical nodes 1 and the optical node 5 . 


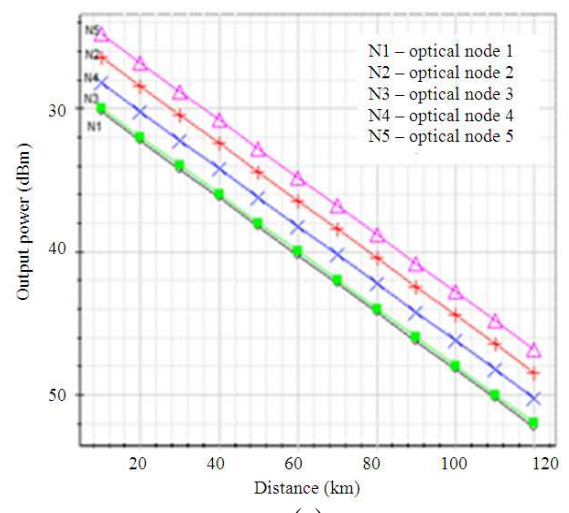

(a)

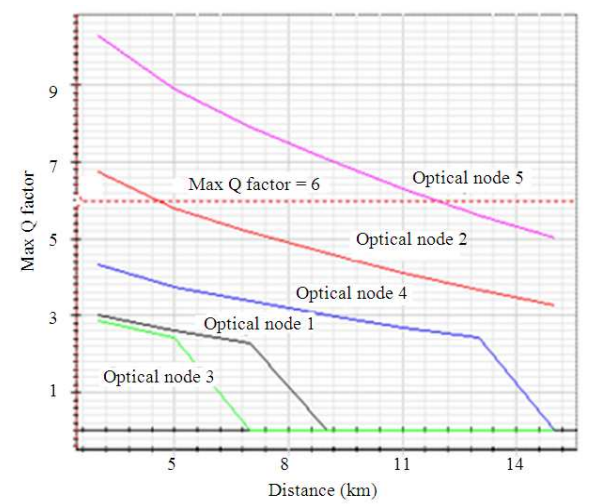

(b)

Fig. 4: Rajah (a) Output power $(\mathrm{dBm})$ versus achievable distance $(\mathrm{km})$ for optical nodes. (b) Maximu Q factor measured for drop signal at sensitivity $-25 \mathrm{dBm}$

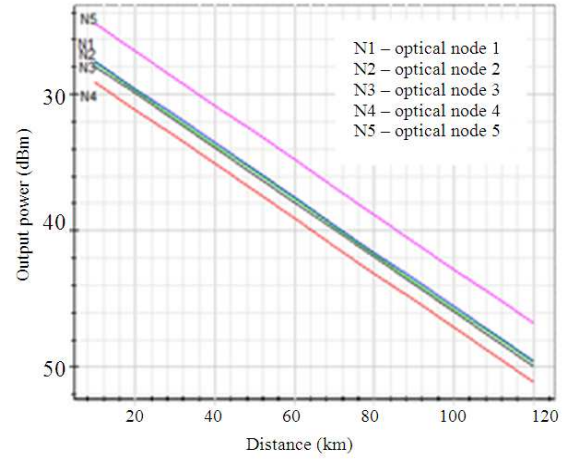

(a)

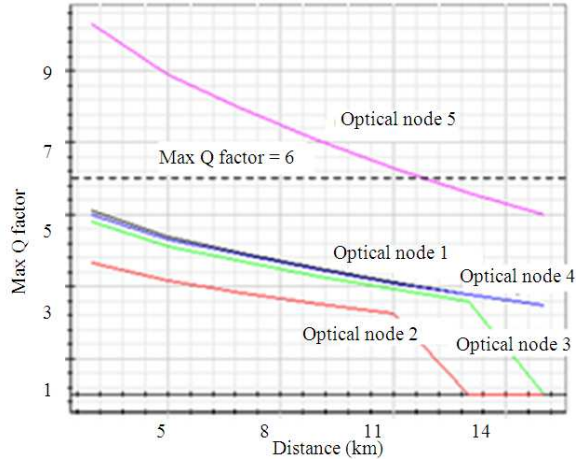

(b)

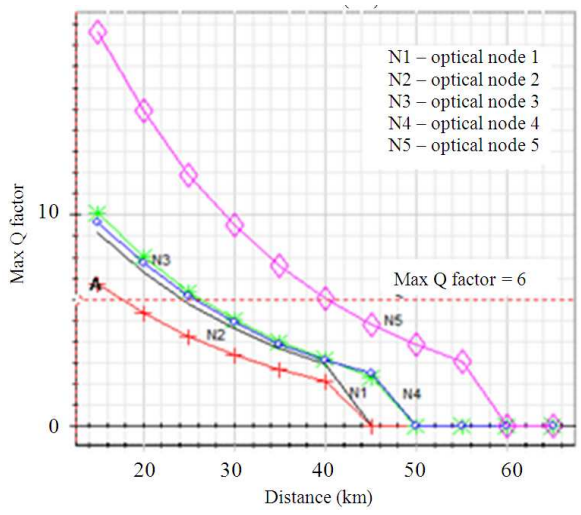

(c)

Fig. 5: (a) Output power $(\mathrm{dBm})$ versus achievable distance $(\mathrm{km})$ for drop signal . (b) Maximum $\mathrm{Q}$ factor versus achievable distance $(\mathrm{km})$ (for drop signal) at sensitivity of $-25 \mathrm{dBm}$. (c) Minimum distance is at $17.5 \mathrm{~km}$ while maximum distance is $40.9 \mathrm{~km}$ according to Max $\mathrm{Q}$ factor at sensitivity of $-30 \mathrm{dBm}$

\section{CONCLUCION}

As a conclusion, design of protection for applications in scattered placements has been developed and analysis is performed by simulation. The design consists of an optical node and CAPU as an additional element that is used to come out with the protection scheme in order to repair the three levels of failure in fiber line. The combination of the ring and tree topology has been used in this design to reach a better 
design protection. So, there are three ways that signal would pass which is linear $\mathrm{L} 2 \mathrm{~L}$ and $\mathrm{C} 2 \mathrm{C}$ and ring path as an alternative route in case of fiber failure. In this study we successfully studied the ratio of pass through and drop signal in the case of failure occurs is some point in three network and the tree topology is remained unchanged or can still be used. The result of received power analysis is represented by the maximum distance can be achieved for every node according to the ratio of pass through and drop signal.

\section{ACKNOWLEDGEMENT}

This project is supported by Universiti Kebangsaan Malaysia (UKM) through the action/strategy research grant UKM-PTS-082-2010 and research university operating fund UKM-OUP-ICT-36-182/2010

\section{REFERENCES}

Ab-Rahman, M.S., 2011c. The extension of oxadm survivability scheme to feeder region in fiber-to-the home (ftth) network. J. Applied Sci. Res., 7: 873879.

Ab-Rahman, M.S., K. Jumari and S. Shaari, 2011b. The feasibility analysis on tree-based EPON-FTTH protection architecture; the art of access control system. J. Applied Sci. Res., 7: 498-506.

Ab-Rahman, M.S., M. Tanra, S.C.R. Boonchuan, A. Baharudin and K.S.A. Mohamad et al., 2011a. Analysis of components failure, malfunction effect and prevention technique in customer access network FTTH-PON. J. Applied Sci., 11: 201-211. DOI: 10.3923/jas.2011.201.211

Ab-Rahman, M.S., S.A.C Aziz and K. Jumari, 2009. Protection for an immediate split structure of treebased epon architecture; ideal condition analysis. Am. J. Eng. Applied Sci., 2: 372-380. DOI: 10.3844/ajeassp.2009.372.380
Appelman, R. and Z. Zalevsky, 2004. All-optical switching technologies for protection applications. IEEE Commun. Mag., 42: S35-S40. DOI: 10.1109/MCOM.2004.1362548

Aziz, S.A.C., M.S. Ab-Rahman and K. Jumari, 2009 Customer access protection unit for survivable FTTH network. Proceedings of International Conference on Space Science and Communication. 26-27 Oct, pp: 71-73, Negeri Sembilan, DOI: 10.1109/ICONSPACE.2009.5352668

Chan, T.K., C.K. Chan, L.K. Chen and F. Tong, 2003. A self protected architecture for wavelengthdivision $M$ passive optical network. Photon. Technol. Let., 15: 1660-1662. DOI: 10.1109/LPT.2003.818657

Han, K.E., S.H. Shim, B.J. Oh, L.M. Peng and Y.C. Kim, 2007. Hybrid protection architecture against multipoint failure in WDM-PON. Proceeding of the 9th International Conference on Advanced Communication Technology. Feb. 12-14, IEEE Xploor, Gangwon, pp: 1385-1390. DOI: 10.1109/ICACT.2007.358615

Hossain, D., H. Erkan, R. Dorsinville, M. Ali and S. Shami et al., 2005. Protection for a ring-based EPON architecture. Proc. 2nd Broadband Networks, 2: 1548-1553. DOI: 10.1109/ICBN.2005.1589790

Langer, K.D., J. Grubor and K. Habel, 2004. Promising evolution paths for passive optical access networks. Proc. Trans. Optical Networks, 1: 202-207. DOI: 10.1109/ICTON.2004.1360276

Rejeb, R., M.S. Leeson, C.M. Machuca and I. Tomkos, 2010. Control and management issues in all-optical networks. J. Networks, 5: 132-139. DOI: 10.4304/jnw.5.2.132-139

Zhao, X., X. Chen and X. Fu, 2005. A novel protection switching scheme for PONs with ring plus tree topology. Proc. SPIE, 6022: 949-956. DOI: $10.1117 / 12.636269$ 